\title{
Alzheimer's Disease and Its Association With Bone Health: A Case-Control Study
}

Sameet Kumar ${ }^{1}$, Aakash Chandnani ${ }^{2}$, Norah H. Aung ${ }^{3,4}$, Simra Shahid ${ }^{5}$, Dua Bukhari ${ }^{2}$, Sania Shahzad ${ }^{6}$ , Besham Kumar ${ }^{6}$, Sidra Memon ${ }^{2}$

1. Internal Medicine, Chandka Medical College, Karachi, PAK 2. Internal Medicine, Jinnah Sindh Medical University, Karachi, PAK 3. Health Sciences, Western Illinois University, Macomb, USA 4. Internal Medicine, University of Medicine 1, Yangon, MMR 5. Medicine, Jinnah Sindh Medical University, Karachi, PAK 6. Internal Medicine, Jinnah Postgraduate Medical Centre, Karachi, PAK

Corresponding author: Besham Kumar, beshamkumar916@gmail.com

\section{Abstract}

\section{Introduction}

Alzheimer's disease is associated with low bone mineral density. Various studies have linked early-onset Alzheimer's disease with bone health. In this study, we will determine the association between bone health and recently diagnosed Alzheimer's disease in the local population.

\section{Methods}

This case-control study was conducted at the neurology unit from April 2019 to Sept 2019. One hundred and fifty (150) Alzheimer's patients with recently (within the last six months) confirmed diagnoses, based on clinical symptoms, mental status, and computed tomography (CT) scan, were included from the neurology outpatient department. The gender and age-matched 150 healthy participants were included in the study as the reference group. Various parameters of bone health and mental status were measured.

\section{Results}

Participants with Alzheimer's had a significantly lower level of serum vitamin D $(15.2 \pm 4.2 \mathrm{ng} / \mathrm{mL}$ vs. $27.5 \pm$ $8.1 \mathrm{ng} / \mathrm{mL}$, p-value: $<0.0001)$ and lower level of serum osteocalcin $(4.3 \pm 1.7 \mathrm{ng} / \mathrm{L} \mathrm{vs.} 5.6 \pm 2.0 \mathrm{ng} / \mathrm{L}$, p-value: $<0.0001)$. Participants with Alzheimer's disease had more people with T-score $\leqslant-2.5$ as compared to the general population $(52.0 \%$ vs. $16.6 \%$, $\mathrm{p}$-value $<0.0001)$.

\section{Conclusion}

Alzheimer's disease is associated with poor bone health as compared to the general population of the same age. Bone health can be an important parameter to screen patients at risk of Alzheimer's disease. The management of Alzheimer's disease should include a regular assessment of bone health, and the treatment plan should include therapies to improve bone health.

Review began 03/04/2021 Review ended 03/06/2021 Published 03/08/2021

\section{() Copyright 2021}

Kumar et al. This is an open access article distributed under the terms of the Creative Commons Attribution License CC-BY 4.0., which permits unrestricted use, distribution, and reproduction in any medium, provided the original author and source are credited.
Categories: Neurology

Keywords: bone mass density, alzhemier's disease, association

\section{Introduction}

Alzheimer's disease is an irreversible neurodegenerative disorder that results in progressive cognitive decline. It is caused by an abnormal buildup of misfolded proteins in the brain, which includes neurofibrillary tangles intracellularly and amyloid protein deposits extracellularly [1]. This disease has multifactorial foreplay, with both genetic and environmental factors. Various factors such as advancing age, female gender, and the presence of apolipoprotein $\mathrm{E} 4$ have shown to pose an increased risk amongst many others [2]. One of the factors that have been linked to the development of early-onset Alzheimer's disease is low bone mineral density (BMD) [2]. Various epidemiological studies have shown that Alzheimer's disease, osteoporosis, and osteopenia happen at the same time in the older population and maybe interlinked [3].

A study conducted in 2005, showed that $11.11 \%$ of females in the lowest quartile of femoral neck BMD developed Alzheimer's disease (AD), whereas 6.0\% of females in the other three quartiles developed $\mathrm{AD}$, concluding that low $\mathrm{BMD}$ raised the risk of $\mathrm{AD}$ in female patients by more than two folds [4]. In a recent study, in 2020, bone metabolic biomarkers were measured in male patients with early-onset AD. They were found to be closely related confirming low bone mineral density as an independent risk factor for the early development of $\mathrm{AD}[5]$.

There are no data available demonstrating the prevalence of low bone mineral density in the Alzheimer's population of Pakistan. In this study, we will compare the BMD, vitamin D levels, serum calcium levels, and 


\section{Cureus}

serum osteocalcin levels between patients with Alzheimer's disease and healthy individuals.

\section{Materials And Methods}

This case-control study was conducted at the neurology unit from April 2019 to Sept 2019 in a tertiary care hospital in Pakistan. One hundred and fifty (150) Alzheimer's patients with recently (within the last six months) confirmed diagnoses, based on clinical symptoms, mental status, and computed tomography (CT) scan, were included from the neurology outpatient department. The gender and age-matched 150 healthy participants were included in the study as the reference group. All patients were not taking any sort of vitamin D supplements. Ethical review board approval was taken before enrollment of participants. Informed consent was taken from participants or attendants where the participant was incapable of giving informed consent.

Age, gender, smoking status, body mass index (BMI), and physical activity were noted in a self-structured questionnaire. The Mini-Mental State Examination (MMSE) scale was used to measure cognitive function. After the assessment of patients, blood was taken via phlebotomy and send to the laboratory to assess serum vitamin D levels, serum calcium levels, and serum osteocalcin levels. A bone mass density (BMD) test was done to evaluate the status of bone health. T-score less than or equal to minus one (-1) was considered normal bone destiny, T-score between minus one (-1) to minus two point five $(-2.5)$ was considered as osteopenia, and score more than minus two point five (-2.5) was labeled as having osteoporosis [6].

Statistical analysis was done using the Statistical Package for the Social Sciences (SPSS) v. 23.0 (IBM Corp, Armonk, New York). Continuous variables were analyzed via descriptive statistics and were presented as means and standard deviations (SDs) while categorical variables were presented as frequency and percentages. T-test and Chi-square were applied as appropriate. Relative risk (RR) was used to compare the interventional group with the placebo. A p-value of less than 0.05 meant that there was a significant difference between the two groups and the null hypothesis was void.

\section{Results}

Age, gender, BMI, and smoking status were comparable between both groups. The MMSE was lower in Alzheimer's patients as compared to the reference group $(21.4 \pm 54.9$ vs. $25.9 \pm 5.6$, p-value; < 0.0001$)$ (Table 1).

\begin{tabular}{|c|c|c|c|}
\hline Characteristics & Alzheimer's Group ( $n=150)$ & Reference Group ( $n=150)$ & P-Value \\
\hline Age in years (Mean $\pm \mathrm{SD}$ ) & $65 \pm 10$ & $64 \pm 12$ & Not significant \\
\hline Male (\%) & 50 & 53.3 & Not significant \\
\hline Body mass index greater than $25 \mathrm{~kg} / \mathrm{m} 2(\%)$ & 29.3 & 26.6 & Not significant \\
\hline Current Smokers (\%) & 10 & 14 & Not significant \\
\hline Mini-mental Status Examination & $21.4 \pm 5.9$ & $25.9 \pm 5.6$ & $<0.0001$ \\
\hline
\end{tabular}

TABLE 1: Comparison of Characteristics of Case and Control Group

Abbreviation: kg; kilogram, m; meter

Participants with Alzheimer's had a significantly lower level of serum vitamin D $(15.2 \pm 4.2 \mathrm{ng} / \mathrm{mL}$ vs. $27.5 \pm$ $8.1 \mathrm{ng} / \mathrm{mL}$, p-value: < 0.0001) and a lower level of serum osteocalcin $(4.3 \pm 1.7 \mathrm{ng} / \mathrm{L}$ vs. $5.6 \pm 2.0 \mathrm{ng} / \mathrm{L}$, pvalue: $<0.0001)$. Participants with Alzheimer's disease had more people with T-score $\leqslant-2.5$ as compared to the general population $(52.0 \%$ vs. $16.6 \%$, p-value $<0.0001)$ (Table 2$)$. 


\section{Cureus}

\begin{tabular}{|c|c|c|c|}
\hline Bone Health & Alzheimer's Group ( $n=150)$ & Reference Group ( $n=150)$ & P-Value \\
\hline Serum Calcium Level (mg/dL) & $8.2 \pm 2.1$ & $8.4 \pm 2.0$ & Not significant \\
\hline Serum Vitamin D Level (ng/mL) & $15.2 \pm 4.2$ & $27.5 \pm 8.1$ & $<0.0001$ \\
\hline Serum Osteocalcin (ng/L) & $4.3 \pm 1.7$ & $5.6 \pm 2.0$ & $<0.0001$ \\
\hline \multicolumn{4}{|l|}{ BMD Score } \\
\hline T-score $\geq-1$ & $20(13.3)$ & 26 (17.3) & \multirow{3}{*}{$<0.0001$} \\
\hline T-core between -1 and -2.5 & $52(34.6)$ & $99(66.0)$ & \\
\hline T-score $\leq-2.5$ & $78(52.0)$ & 25 (16.6) & \\
\hline
\end{tabular}

\section{TABLE 2: Comparison of Bone Health Status of Case and Control Group}

Abbreviation: mg; milligram, dL; deciliter, ng; nanogram. L; liter, BMD; bone mineral density

\section{Discussion}

In 2010, Alzheimer's disease was prevalent in around $6 \%$ of the world's population, with $58 \%$ of the total Alzheimer's population belonging to low-middle income countries, and was expected to rise in the years to come [7]. One of the modifiable risk factors identified to the early development of AD is BMD. Our results concluded that a total of 130/150 (86.7\%) Alzheimer's patients presented with low bone mineral density, with 78/150 (52\%) being severely affected and discovered to have co-existent osteoporosis (T-score $\leqslant-2.5$ ).

Our study showed significantly lower vitamin D levels in the Alzheimer's population $(15.2 \mathrm{ng} / \mathrm{ml})$ as compared to the control group $(27.5 \mathrm{ng} / \mathrm{ml})$. In a meta-analysis conducted in 2012 , it was concluded that serum vitamin $\mathrm{D}$ concentrations in $\mathrm{AD}$ patients lay 1.4 standard deviations below healthy individuals, labeling it as a potential biomarker for $\mathrm{AD}$ and a contributor to declining cognitive function [8-9]. Vitamin D deficiency leads to an increase in the PTH levels, which is further implicated in hastening the decline in mini-mental status scores [10]. Several mechanisms have been proposed but no clear understanding of its pathophysiology has yet been achieved [11]. It is speculated that both the disorders share a common etiology; abnormally expressed amyloid depositions in the brain can cause $\mathrm{AD}$, whereas when deposited in the bone, they interfere with the receptor activator of nuclear factor-kappa-B ligand (RANKL) signaling cascade leading to an increase in osteoclastic activity thereby, decreasing the BMD and leading to the development of osteoporosis [12].

Similar to our findings, a study conducted in China established a link between osteoporosis and the development of $\mathrm{AD}$; subjects in the lowest quartile of BMD were shown to carry a two-fold increased risk of progression to $\mathrm{AD}$ as compared to the healthy population [13]. According to our study, $86.7 \%$ of the Alzheimer's population presented with low BMD but a significant $82.6 \%$ of the control population was also discovered to have low BMD. This can be explained by the high prevalence of osteopenia in the Asian population. In a study based in Tehran, it was discovered that regardless of the age, their population had peak bone mass lower than that of the equivalent European or American population [14]. Studies conducted in Pakistan have also shown that the majority of the population, including both men and women, tend to have low BMD [15-16]. However, as per our study, Alzheimer's population is affected in a greater proportion and much more severe intensity with the majority lying under a T-score of -2.5 . In our study, $52 \%$ of the Alzheimer's population was found to have concomitant osteoporosis as compared to $16.6 \%$ of the control population. This strongly associates the two comorbid together suggesting an intrinsic link between the pathogenesis of both diseases. With the establishment of this relation, Alzheimer's patients should be offered dual-energy X-ray absorptiometry (DEXA) scanning to screen for osteoporosis along with appropriate management, which could improve the outcomes of Alzheimer's progression as it shares the same risk factors. Vitamin D supplementation has been proposed to prevent neurodegeneration in these patients, but further studies are still required to collect sufficient data to comment on its efficacy [17]. In a recent study, the use of vitamin D binding proteins (DBPs), which have been shown to suppress amyloidrelated pathology in the brain, has been proposed to slow down the progression of cognitive decline in $\mathrm{AD}$ [18-19].

To the best of our knowledge, this is the first study that studies the association between bone health and Alzheimer's disease. However, the study has its limitation as well. First, since the study was at a single institute, sample size diversity was reduced. Second, because the study was case-control in nature, a causal relationship between $\mathrm{BMD}$ and $\mathrm{AD}$ cannot be established. 


\section{Conclusions}

Alzheimer's disease is associated with poor bone health as compared to the general population of the same age. Bone health can be an important parameter to screen patients at risk of Alzheimer's disease. The management of Alzheimer's disease should include a regular assessment of bone health, and the treatment plan should include therapies to improve bone health. Further large-scale prospective studies are needed to establish bone health as a risk factor for Alzheimer's disease.

\section{Additional Information}

\section{Disclosures}

Human subjects: Consent was obtained or waived by all participants in this study. Jinnah Sindh Medical University issued approval JSMU/S/IRB/0/89. Animal subjects: All authors have confirmed that this study did not involve animal subjects or tissue. Conflicts of interest: In compliance with the ICMJE uniform disclosure form, all authors declare the following: Payment/services info: All authors have declared that no financial support was received from any organization for the submitted work. Financial relationships: All authors have declared that they have no financial relationships at present or within the previous three years with any organizations that might have an interest in the submitted work. Other relationships: All authors have declared that there are no other relationships or activities that could appear to have influenced the submitted work.

\section{References}

1. Smith MA: Alzheimer disease. Int Rev Neurobiol. 1998, 42:1-54. 10.1016/S0074-7742(08)60607-8

2. Lindsay J, Laurin D, Verreault R, et al.: Risk factors for Alzheimer's disease: a prospective analysis from the Canadian study of health and aging. Am J Epidemiol. 2002, 156:445-453. 10.1093/aje/kwf074

3. Downey CL, Young A, Burton EF, Graham SM, Macfarlane RJ, Tsapakis E-M, Tsiridis E: Dementia and osteoporosis in a geriatric population: is there a common link?. World J Orthop. 2017, 8:412-423. 10.5312/wjo.v8.i5.412

4. Tan ZS, Seshadri S, Beiser A, et al.: Bone mineral density and the risk of Alzheimer disease . Arch Neurol. 2005, 62:107-111. 10.1001/archneur.62.1.107

5. Pu Z, Tang X, Fei Y, Hou Q, Lin Y, Zha X: Bone metabolic biomarkers and bone mineral density in male patients with early-stage Alzheimer's disease. Eur Geriatr Med. 2020, 11:403-408. 10.1007/s41999-02000289-z

6. Faulkner KG, Orwoll E: Implications in the use of T-scores for the diagnosis of osteoporosis in men . J Clin Densitom. 2002, 5:87-93. 10.1385/JCD:5:1:087

7. Wimo A, Jönsson L, Bond J, Prince M, Winblad B: The worldwide economic impact of dementia 2010. Alzheimers Dement. 2013, 9:1-11.10.1016/j.jalz.2012.11.006

8. Annweiler C, Llewellyn DJ, Beauchet O: Low serum vitamin D concentrations in Alzheimer's disease: a systematic review and meta-analysis. J Alzheimers Dis. 2013, 33:659-674. 10.3233/JAD-2012-121432

9. Balion C, Griffith LE, Strifler L, et al.: Vitamin D, cognition, and dementia. A systematic review and metaanalysis. Neurology. 2012, 79:1397-1405. 10.1212/WNL.0b013e31826c197f

10. Björkman MP., Sorva AJ, Tilvis RS: Does elevated parathyroid hormone concentration predict cognitive decline in older people?. Aging Clin Exp Res. 2010, 22:164-169. 10.1007/BF03324791

11. Lourida I, Thompson-Coon J, Dickens CM, Soni M, Kuźma E, Kos K, Llewellyn DJ: Parathyroid hormone, cognitive function and dementia: a systematic review. PLoS One. 2015, 2015:0127574. 10.1371/journal.pone.0127574

12. Chen YH, Lo RY: Alzheimer's disease and osteoporosis. Tzu-Chi Med J. 2017, 29:138-142. 10.4103/tcmj.tcmj_54_17

13. Zhou R., Zhou H, Rui L, Xu J: Bone loss and osteoporosis are associated with conversion from mild cognitive impairment to Alzheimer's disease. Curr Alzheimer Res. 2014, 11:706-713.

14. Chen YH, Lo RY: Alzheimer's disease and osteoporosis. Tzu-Chi Med J. 2017, 29:138-142. 10.4103/tcmj.tcmj_54_17

15. Larijani B, Hossein NA, Mojtahedi A, et al.: Normative data of bone mineral density in healthy population of Tehran, Iran: a cross sectional study. BMC Musculoskelet Disord. 2005, 6:38. 10.1186/1471-2474-6-38

16. Masood Z, Shahzad S, Saqib A, Ashraf K: Osteopenia and osteoporosis; frequency among females . Professional Med J. 2014, 21:477-483.

17. Akbar W, Ahmad S, Anwar J, et al.: Osteoporosis, osteopenia in men of Mardan region. J BKMC. 2017, 1:1317.

18. Banerjee A, Khemka VK, Ganguly A, Roy D, Ganguly U, Chakrabarti S: Vitamin D and Alzheimer's disease: neurocognition to therapeutics. Int J Alzheimers Dis. 2015, 2015:1-11. 10.1155/2015/192747

19. Moon M, Song H, Hong HJ, et al.: Vitamin D-binding protein interacts with $A \beta$ and suppresses $A \beta$-mediated pathology. Cell Death Differ. 2013, 20:630-638. 10.1038/cdd.2012.161 